\title{
CONQUERING THE INTOLERABLE BURDEN OF MALARIA: WHAT'S NEW, WHAT'S NEEDED: A SUMMARY
}

\author{
JOEL G. BREMAN, MARTIN S. ALILIO, AND ANNE MILLS \\ Disease Control Priorities in Developing Countries Project, Fogarty International Center, National Institutes of Health, \\ Bethesda, Maryland; Department of Health Economics and Policy, London School of Hygiene and Tropical Medicine, \\ London, United Kingdom
}

\begin{abstract}
Each year, up to three million deaths due to malaria and close to five billion episodes of clinical illness possibly meriting antimalarial therapy occur throughout the world, with Africa having more than $90 \%$ of this burden. Almost $3 \%$ of disability adjusted life years are due to malaria mortality globally, $10 \%$ in Africa. New information is presented in this supplement on malaria-related perinatal mortality, occurrence of human immunodeficiency virus in pregnancy, undernutrition, and neurologic, cognitive, and developmental sequelae. The entomologic determinants of transmission and uses of modeling for program planning and disease prediction and prevention are discussed. New data are presented from the Democratic Republic of the Congo, Tanzania, Ethiopia, and Zimbabwe on the increasing urban malaria problem and on epidemic malaria. Between $6 \%$ and $28 \%$ of the malaria burden may occur in cities, which comprise less than $2 \%$ of the African surface. Macroeconomic projections show that the costs are far greater than the costs of individual cases, with a substantial deleterious impact of malaria on schooling of patients, external investments into endemic countries, and tourism. Poor populations are at greatest risk; $58 \%$ of the cases occur in the poorest $20 \%$ of the world's population and these patients receive the worst care and have catastrophic economic consequences from their illness. This social vulnerability requires better understanding for improving deployment, access, quality, and use of effective interventions. Studies from Ghana and elsewhere indicate that for every patient with febrile illness assumed to be malaria seen in health facilities, 4-5 episodes occur in the community. Effective actions for malaria control mandate rational public policies; market forces, which often drive sales and use of drugs and other interventions, are unlikely to guarantee their use. Artemisinin-based combination therapy (ACT) for malaria is rapidly gaining acceptance as an effective approach for countering the spread and intensity of Plasmodium falciparum resistance to chloroquine, sulfadoxine/pyrimethamine, and other antimalarial drugs. Although costly, ACT (\$1.20-2.50 per adult treatment) becomes more cost-effective as resistance to alternative drugs increases; early use of ACT may delay development of
\end{abstract} resistance to these drugs and prevent the medical toll associated with use of ineffective drugs.

The burden of malaria in one district in Tanzania has not decreased since the primary health care approach replaced the vertical malaria control efforts of the 1960s. Despite decentralization, this situation resulted, in part, from weak district management capacity, poor coordination, inadequate monitoring, and lack of training of key staff. Experience in the Solomon Islands showed that spraying with DDT, use of insecticide-treated bed nets (ITNs), and health education were all associated with disease reduction. The use of nets permitted a reduction in DDT spraying, but could not replace it without an increased malaria incidence. Baseline data and reliable monitoring of key outcome indicators are needed to measure whether the ambitious goals for the control of malaria and other diseases has occurred. Such systems are being used for evidence-based decision making in Tanzania and several other countries. Baseline cluster sampling surveys in several countries across Africa indicate that only $53 \%$ of the children with febrile illness in malarious areas are being treated; chloroquine (CQ) is used $84 \%$ of the time, even where the drug may be ineffective. Insecticide-treated bed nets were used only $2 \%$ of the time by children less than five years of age. Progress in malaria vaccine research has been substantial over the past five years; 35 candidate malaria vaccines are in development, many of which are in clinical trials. Development of new vaccines and drugs has been the result of increased investments and formation of publicprivate partnerships. Before malaria vaccine becomes deployed, consideration must be given to disease burden, costeffectiveness, financing, delivery systems, and approval by regulatory agencies. Key to evaluation of vaccine effectiveness will be collection and prompt analysis of epidemiologic information. Training of persons in every aspect of malaria research and control is essential for programs to succeed. The Multilateral Initiative on Malaria (MIM) is actively promoting research capacity strengthening and has established networks of institutions and scientists throughout the African continent, most of whom are now linked by modern information-sharing networks. Evidence over the past century is that successful control malaria programs have been linked to strong research activities. To ensure effective coordination and cooperation between the growing number of research and control coalitions forming in support of malaria activities, an umbrella group is needed. With continued support for scientists and control workers globally, particularly in low-income malarious countries, the long-deferred dream of malaria elimination can become a reality.

\section{INTRODUCTION}

\section{"Ex Africa semper aliquid novi" \\ ("There is always something new coming out of Africa") \\ Gaius Plinius Secundus (Pliny the Elder), AD 23-79}

There has been rapidly increasing optimism for greatly improved malaria control, particularly in Africa where the vast majority of people affected by the disease reside (Figure 1). This new positive attitude is based on major advances in ma- laria research and public health practices, and careful epidemiologic and economic analyses of malaria's burden and costeffective ways to lessen it. Most crucial has been heretofore unheard of political, strategic, and financial support for malaria scientific studies and control actions. The support has come from a variety of recently formed coalitions-from the scientific and policy-making communities in countries most affected by the disease, by formation of public-private partnerships to develop new drugs and vaccines, from national and international organizations that had not traditionally sup- 


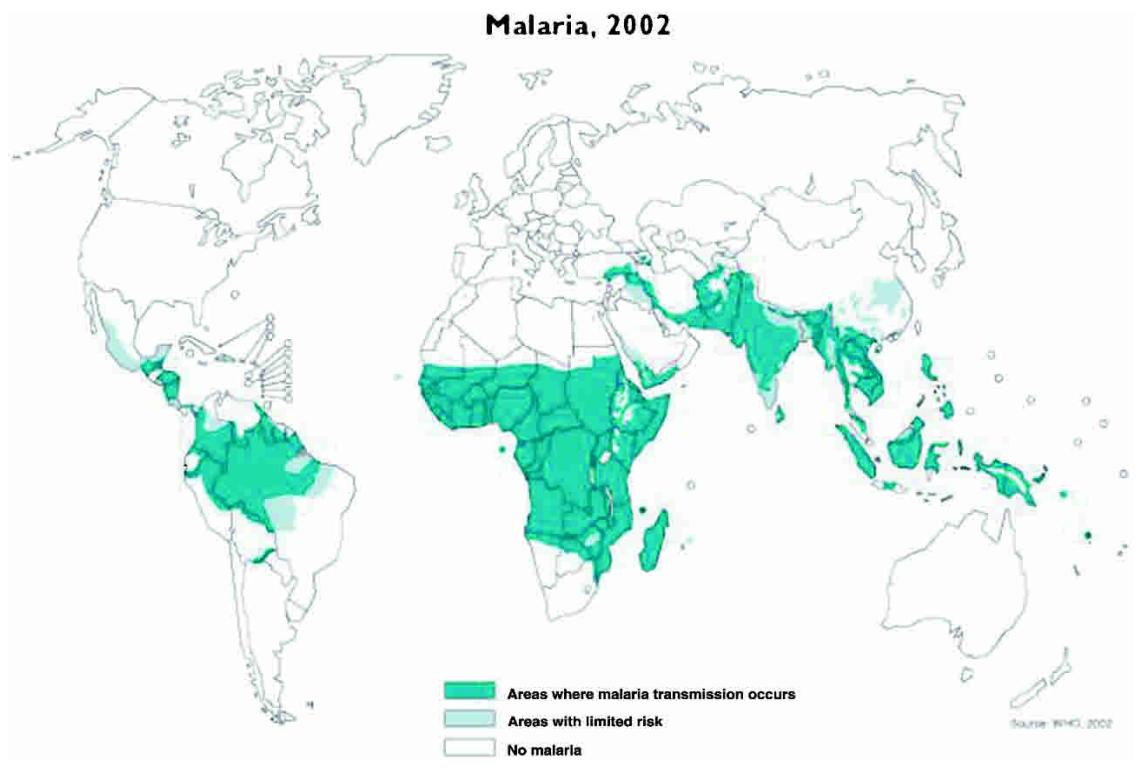

FIgURE 1. Malaria, 2002. Source: World Health Organization, 2002.

ported malaria work, from foundations such as the Wellcome Trust, with a long history of malaria research support, and those more recently committed to malaria research, operations, and training such as the Fogarty International Center, National Institutes of Health (NIH), the Howard Hughes Medical Institute, the Ellison Foundation, the United Nations Children's Fund (UNICEF), the European Commission, and the Bill \& Melinda Gates Foundation. The Global Fund for human immunodeficiency virus/acquired immunodeficiency virus (HIV/AIDS), Tuberculosis and Malaria (Global Fund), the MIM, the Medicines for Malaria Venture (MMV), the Malaria Vaccine Initiative (MVI), the African Malaria Network Trust (AMANET), the Gates Malaria Partnership based at the London School of Hygiene and Tropical Medicine, and the Malaria Research Institute at the Johns Hopkins University Bloomberg School of Public Health are just a few of the new initiatives focusing on malaria that bring added perspective, innovation, energy, and resources to the growing malaria-related budgets and programs. Major growth in malaria research and control programs has also occurred in organizations with a long commitment to malaria work-the National Institute of Allergy and Infectious Diseases (NIAID, NIH), Centers for Disease Control and Prevention (CDC), U.S. Agency for International Development (USAID), World Health Organization (WHO), and many other organizations. A resounding call for more efforts to better understand and control malaria came from representatives of 44 of the 50 African malarious countries who met in Abuja, Nigeria, in 2000 and vowed to bring national and international attention and resources to battle this perennial peril. ${ }^{1}$

The Third MIM Pan-African Conference on Malaria was held in Arusha, Tanzania on November 18-22, 2002 with the theme "Global Advances in Malaria Research: EvidenceBased Decision Making for Malaria Control and Policy." At the Conference, an all-day symposium was held on "The Intolerable Burden of Malaria: What's New, What's Needed." There were 18 speakers who addressed new insights from clinical, epidemiologic, immunologic, entomologic, public health, economic, and public policy research. Selected papers from this symposium, and others subsequently invited, have been assembled in this second supplement to the American Journal of Tropical Medicine and Hygiene devoted to highlighting the "intolerable burden of malaria". The first supplement, published in 2001, focused mainly on defining the clinical and epidemiologic burden and its components. ${ }^{2}$ These articles, summarized here, go beyond the first edition by addressing newer findings. The goal, once again, is to promote research by African scientists and colleagues elsewhere to improve our understanding of malaria, develop new tools to combat it, and, ultimately, eliminate this scourge.

\section{BURDEN}

Morbidity, mortality, and disability from malaria (and other diseases) are now being summarized in a new metric, disability-adjusted life years (DALYs), an aggregate measure of premature mortality, morbidity, and disability, which can also be used for analyzing cost-effectiveness of the major interventions. ${ }^{3}$ The WHO calculates the burden of malaria and other diseases based on an assessment of global DALYs, with apportionment of each disease contribution based on selected epidemiologic data and estimates from field studies. This approach does not lend itself to reflecting uncertainty ranges and, for malaria, the burdens resulting from the many clinical manifestations of disease, some of which are still being defined. ${ }^{4-6}$ Tables 1 and 2 show the global burden of malaria mortality and DALYs derived from deaths reported by the WHO. ${ }^{7}$ The African continent shows the greatest effects of this disease, accounting for more than $90 \%$ of the burden, including African countries in the Eastern Mediterranean Region of WHO, followed by Southeast Asia with almost $9 \%$ of the burden. Malaria deaths are responsible for almost 3\% of the world's DALYs (>10\% in Africa), not counting the considerable and imprecisely quantified burden due to morbidity and disability. Despite advances in understanding malaria ecology, and development of interventions, more than $50 \%$ of the world's population is exposed to malaria. This is an increase of close to $10 \%$ over the past decade. ${ }^{8}$

Figure 2 shows the many clinical manifestations of malaria and their sequelae. Table 3 shows malaria mortality and mor- 
TABLE 1

Deaths and malaria-related deaths (1,000s), 2000*

\begin{tabular}{|c|c|c|c|c|}
\hline & Population & $\begin{array}{l}\text { All deaths } \\
(\%)\end{array}$ & $\begin{array}{c}\text { Malaria deaths } \\
(\%)\end{array}$ & $\underset{(\%)}{\text { Malaria/total }}$ \\
\hline World & $6,122,210$ & 56,554 & 1,124 & 2.0 \\
\hline Africa & 655,476 & $10,681(18.9)$ & $963(85.7)$ & 9.0 \\
\hline Americas & 837,967 & $5,911(10.5)$ & $1(-)$ & 0.02 \\
\hline Eastern Mediterranean & 493,091 & $4,156(7.3)$ & $55(4.9)$ & 1.3 \\
\hline Europe & 874,178 & $9,703(17.2)$ & 0 & - \\
\hline Southeast Asia & $1,559,810$ & $14,467(25.6)$ & $95(8.5)$ & 0.7 \\
\hline Western Pacific & $1,701,689$ & $11,636(20.6)$ & $10(0.9)$ & 0 \\
\hline
\end{tabular}

* Adapted from the World Health Organization World Health Report, 2002.

bidity based on an assessment of demography, transmission, potential, and parasite prevalence. Table 4, derived from demographic, clinical, and epidemiologic reports, indicates that the mortality from malaria in Africa alone may be approaching three million, almost three times the WHO estimate. ${ }^{5-7}$ One reason for the discrepancy is the WHO separation of manifestations into direct effects and indirect effects. The direct effects do not include malaria-induced acute and chronic anemia, maternal pathology (including low-birth weight babies), hypoglycemia, and other metabolic imbalances, or longterm neuropsychologic-developmental sequelae-all of which contribute considerable components to the burden. In addition, the WHO calculations do not include malaria's enhancement of the severity of other childhood diseases.

The number of episodes of malaria globally has been difficult to quantify because a substantial percent of the population in endemic areas has parasitemia at any one time and children less than five years of age may have 4-9 or more febrile episodes each year. ${ }^{4}$ Because rapid and precise diagnosis is not available in most endemic areas, WHO, UNICEF, USAID, and individual countries advise treating febrile patients for malaria. One estimate is that outside of southern Africa, up to 4.9 billion febrile events or anti-malarial treatment exposures occur each year in Africa. ${ }^{5}$ This underscores the critical need for reliable, rapid, simple, and inexpensive diagnostics for malaria and other common diseases to assist ill patients, conserve valuable drugs, and prevent emergence of resistant parasites. Apart from the impact of malaria in children, on pregnancy, and on anemia, hypoglycemia, acute respiratory distress, and cerebral malaria dominate the pathology. The great overlap of several clinical manifestations due to and contributed by malaria are shown in Figure 3. ${ }^{9}$

\section{AFRICAN LEADERSHIP IN RESEARCH AND STRENGTHENED LINKAGES TO CONTROL}

Samba highlights the new areas of research opportunity opened by the recent sequencing of the Plasmodium falci- parum and Anopheles gambiae genomes completed about the same time as the full human genetic code. ${ }^{10}$ Will "detailed knowledge of these genomes ... lead to new drugs (vaccines, and diagnostics)?" These fundamental advances, along with those in functional genomics, bioinformatics, immunology, medicinal chemistry, and pharmacology, along with improved understanding of pathogenesis, patient management, disease ecology and control will be most important for decreasing malaria's impact. We fully support the statement "African scientists have a key role to play, in their collaboration with their colleagues from the north and, most importantly, by South-South collaboration."

Ntoumi and others, all prominent African malaria researchers, state that "the goals of malaria control may never be achieved without strong involvement of those scientists who are directly affected by this terrible disease in their daily life" and "until recently, true participation of African scientists in the international effort to control malaria has been minimal."11 The importance of networks to promote connection between African scientists is underscored, and inadequate dialogue between malaria researchers and control managers is lamented. Managers are urged to define the control actions upon which basic and applied research can be directed. Improved methods for monitoring resistance of Plasmodia to drugs and Anopheles to insecticides are two practical examples given for tying research and control together in the field. Concern is expressed about the meager funding for African researchers compared with the problem they face, and the fragmentation of research leadership outside the MIM.

\section{THE MALARIA BURDEN: RETHINKING THE CLINICAL AND EPIDEMIOLOGIC IMPACT}

Snow and others challenge the DALY approach for quantifying cause-specific health burdens. ${ }^{12}$ They state, "for malaria, this categorical approach may not fully capture chronic

TABLE 2

Disability-adjusted life years (DALYs, 1,000s), all cause and malaria-related, 2002*

\begin{tabular}{|c|c|c|c|c|}
\hline & Population & $\begin{array}{l}\text { DALYs from } \\
\text { all deaths (\%) }\end{array}$ & $\begin{array}{l}\text { DALYs from } \\
\text { malaria deaths }(\%)\end{array}$ & $\begin{array}{l}\text { DALYs from } \\
\text { malaria/total (\%) }\end{array}$ \\
\hline World & $6,122,210$ & $1,467,257$ & 42,280 & 2.9 \\
\hline Africa & 655,476 & $357,884(24.4)$ & $36,012(85.2)$ & 10.1 \\
\hline Americas & 837,967 & $145,217(9.9)$ & $108(0.2)$ & 0.07 \\
\hline Eastern Mediterranean & 493,091 & $136,221(9.3)$ & $2,050(4.8)$ & 1.5 \\
\hline Europe & 874,178 & $151,223(10.3)$ & $20(0.04)$ & 0.01 \\
\hline Southeast Asia & $1,559,810$ & $418,844(28.5)$ & $3,680(8.7)$ & 0.9 \\
\hline Western Pacific & $1,701,689$ & $257,868(17.6)$ & $409(1.0)$ & 0.2 \\
\hline
\end{tabular}

* Adapted from the World Health Organization World Health Report, 2002. 


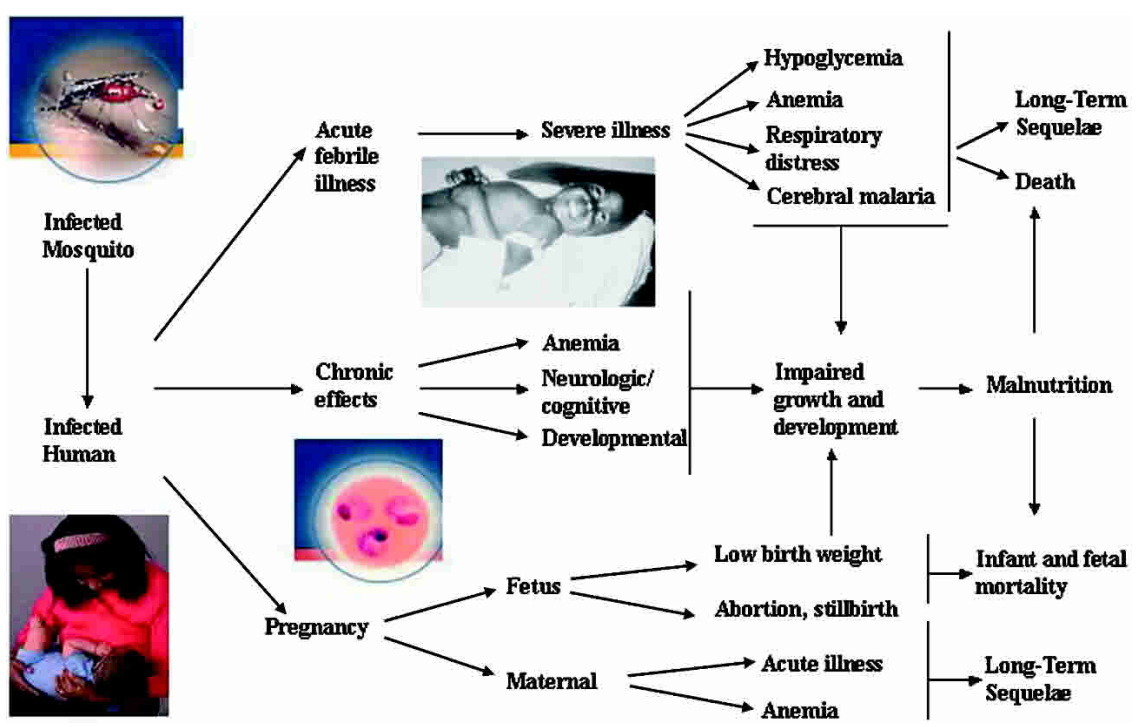

FIGURE 2. Acute, chronic, and pregnancy-related manifestations of malaria.

anemia, low birth weight, and enhancement of the severity of other childhood diseases." In their analysis of the magnitude to which malaria acts a risk factor for all-cause mortality in African children less than five years of age in 48 independent prospective studies, they found that presence of parasites in childhood populations more than doubled all-cause mortality. Between 1982 and 1989 mortality increased from 31 per 1,000 less than five years old with a parasite prevalence of $18 \%$ to 55 per 1,000 less than five years old with a parasite prevalence of $95 \%$. Between 1990 and 1999, mortality increased from 8 to 44 per 1,000 less than five years old over a range of prevalences of $0-95 \%$. The beneficial effect of ITNs on entomologic inoculation rates (EIRs), parasite prevalence, and mortality in Kenya and elsewhere is highlighted by the investigators, and they urge "starting efforts to implement ITN throughout Africa as a priority intervention to improve child survival."

Malaria-induced anemia causes more deaths than any of the other manifestations of this disease. ${ }^{6}$ Children with hemoglobin levels less than 11 gram percent (hematocrit < 33\%) are at particular risk and those with hemoglobin levels less than 5 gram percent (hematocrit $<15 \%$ ) require emergency attention. ${ }^{13}$ Crawley draws attention to the myriad causes and consequences of anemia, particularly iron deficiency and malarial anemia, and the need for careful monitoring of children for anemia starting within the first few months of life in areas of intense and stable malaria transmission; the highest prevalence of anemia occurs toward the end of the child's first year. ${ }^{14}$ An analysis of hemoglobin levels in children in four African countries with intense and stable transmission

TABLE 3

Malaria-related mortality and morbidity in Africa, 2000*

\begin{tabular}{|c|c|c|c|c|}
\hline \multirow[b]{2}{*}{ Condition } & \multirow{2}{*}{$\begin{array}{c}\text { Total } \\
\text { (interquartile range) }\end{array}$} & \multicolumn{3}{|c|}{ Percent by age in years } \\
\hline & & $0-4$ & $5-14$ & $\geq 15$ \\
\hline Malaria-specific mortality & $1,144,572 \dagger(702,957-1,605,48)$ & 65 & 19 & 16 \\
\hline Maternal mortality (anemia) & 5,300 & - & - & 100 \\
\hline Infant mortality (pregnancy-related) & $71,000-190,000$ & 100 & - & - \\
\hline Fatal adverse drug events & 2,300 & $100 ?$ & $?$ & $?$ \\
\hline Fatal HIV from blood transfusion & $5,300-8,500$ & \multicolumn{2}{|c|}{100} & - \\
\hline Epilepsy-related mortality after cerebral malaria or seizures & Unknown & - & $?$ & $?$ \\
\hline Anemia, undernutrition, and HIV mortality from malaria & Unknown & $?$ & $?$ & $?$ \\
\hline Morbidity attacks $(1,000 \mathrm{~s})$ & $213,549(134,322-324.617)$ & 51 & 35 & 14 \\
\hline Morbidity days $(1,000 s)$ & $803,699(494,416-1.298,872)$ & 69 & 21 & 10 \\
\hline \multicolumn{5}{|l|}{ Neurocognitive sequelae after cerebral malaria } \\
\hline Hemiparesis & $360-400$ & \multicolumn{2}{|c|}{100} & $?$ \\
\hline Quadriparesis & $770-860$ & \multicolumn{2}{|c|}{100} & $?$ \\
\hline Hearing impairment & $650-730$ & \multicolumn{2}{|c|}{100} & $?$ \\
\hline Visual impairment & $300-330$ & \multicolumn{2}{|c|}{100} & $?$ \\
\hline Behavioral difficulties & $1,540-1,720$ & \multicolumn{2}{|c|}{100} & $?$ \\
\hline language deficits & $7,000-7,800$ & \multicolumn{2}{|c|}{100} & $?$ \\
\hline Epilepsy & $2,700-3,000$ & \multicolumn{2}{|c|}{100} & $?$ \\
\hline Effect of malaria on cognition & Unknown & $?$ & $?$ & $?$ \\
\hline
\end{tabular}

* Adapted from Snow and others. ${ }^{5}$ HIV = human immunodeficiency virus. (http://www.who.int/whr/2002/en/whr2002_annex2.pdf). 
TABLE 4

Deaths from malaria in Africa in children less than five years of age and total, 2001*

\begin{tabular}{lc}
\hline \multicolumn{1}{c}{ Cause of death } & $\begin{array}{c}\text { Range of deaths in } \\
\text { children }<5 \text { years old }\end{array}$ \\
\hline Cerebral malaria & 110,000 (no range) \\
Severe malarial anemia & $190,000-974,000$ \\
Respiratory distress & 110,000 (no range) \\
Hypoglycemia & $153,000-267,000$ \\
Low birth weight & $62,000-363,000$ \\
Deaths & $625,000-1,824,000$ \\
All malaria deaths in Africa $\dagger$ & $962,000-2,806,000$ \\
\hline$*$ Modified from Murphy and Breman. ${ }^{6}$. \\
$\dagger$ Children $<5$ years of age represent $65 \%$ of all deaths in Africa as per Snow and others. ${ }^{5}$
\end{tabular}

showed that $>80 \%$ of the infants 10 months of age are anemic, and approximately one-third have a hemoglobin level $<8$ gram percent. Anti-anemia interventions targeted to pregnant women and infants, and integrated into antenatal and maternal child health care are described. Use of the HemoCue ${ }^{\circledR}$ hemoglobinometer (HemoCue, Angelholm, Sweden) in the field has simplified measurement of anemia, and every hospital and health clinic with trained staff should have access to this reliable technology. Awareness of common causes of anemia in Africa, such as maternal and childhood nutritional deficiencies (including micronutrients), intestinal helminths, HIV infection, hemoglobinopathies, and malaria, is important to manage patients and prevent the acceleration

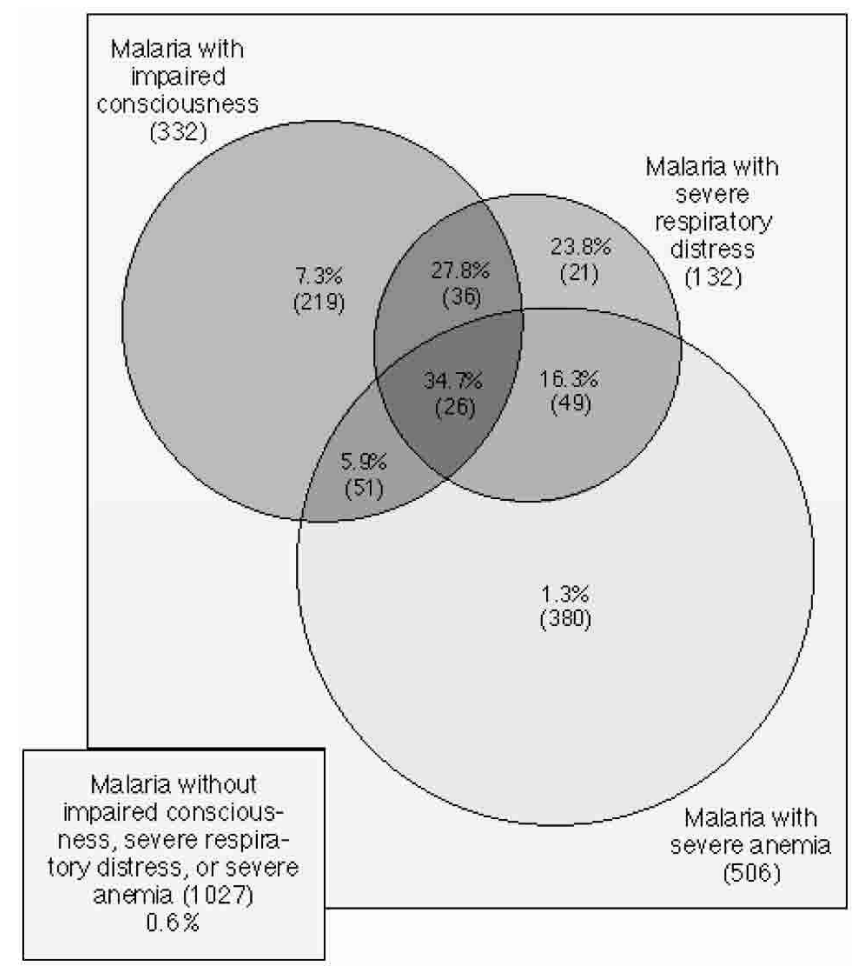

FIGURE 3. Prevalence, overlap, and mortality for the major clinical subgroups of severe malaria. ${ }^{9}$ Values in parentheses are the total number of children (mean age $=26.4$ months) and percentages show mortality rates. Impaired consciousness $=$ deep coma and unable to make a localizing response (Blantrye coma score $\leq 4$ ); severe respiratory distress $=$ chest recession or abnormally deep breathing; severe anemia $=$ hemoglobin levels $<5$ gram percent. of severe consequences of, and death from, anemia. The malaria-specific interventions to prevent anemia are ITNs, chemoprophylaxis, and intermittent preventive treatment of pregnant women (IPT), and, possibly for infants (IPTi), and prompt effective treatment of infections. Deworming with mebendazole and albendazole, treatment of HIV/AIDS, including treatment of opportunistic infections, and selective use of iron, vitamin A, zinc, and complementary food supplements should be considered, and attention given to improved agricultural and eating practices.

Only recently has malaria's dire effects on perinatal mortality been shown. Van Geertruyden and others reviewed 117 studies published since 1948 and report that the perinatal mortality rate (PMR) was 61.1 per 1,000 newborns in malarious countries and 25.8 per 1,000 newborns in non-malarious countries. ${ }^{15}$ Similarly, the fetal mortality rate was higher in malaria-endemic countries. Aware of the many confounding variables in their review, these investigators considered those countries with a low human development index between 500 and 800; again, the PMR was much higher in malaria-endemic countries compared with non-endemic countries. Placental malaria was associated with a higher risk of stillbirths regardless of parity. The IPT of mothers and ITNs are advised to prevent perinatal and fetal mortality from malaria.

The negative effects of co-infection with HIV and malaria during pregnancy have now been shown definitively by ter Kuile and others in their review of 11 studies in Africa. ${ }^{16}$ Pregnant women infected with HIV had "consistently more peripheral and placental malaria (summary relative risk = 1.58 and 1.66, respectively), higher parasite densities, and more febrile illnesses, severe anemia, and adverse birth outcomes (low birth weight, prematurity, intrauterine growth retardation) than HIV-uninfected women, particularly in multigravidae." Malaria in pregnancy was increased by $5.5 \%$ and $18.8 \%$ in populations with $10 \%$ and $40 \%$ HIV prevalence, respectively. Those pregnant women with malaria had a twofold higher HIV-1 viral concentration. Less clear is whether malaria increased mother-to-child transmission of HIV. These investigators urge more research on interactions between antiretroviral drugs, antimalarials, prophylaxis with cotrimoxazole for opportunistic infections, and IPT, including attention to anemia and pharmacovigilance, while strengthening prevention measures for malaria and HIV during pregnancy.

The association between malaria and undernutrition is complex, yet improved nutrition lessens the severity of malaria episodes and results in a decrease in malaria deaths. Caulfield and others report a meta-analysis of the effect of iron supplementation on malaria morbidity and conclude "there was a (statistically) heightened risk of infection and (non-significant) increase in malaria attacks and spleen enlargement with supplementation; however, treatment was associated with significant increases in hemoglobin and decrease in severe anemia." 17 The investigators present their main argument that that "deficiencies in vitamin A, zinc, iron, folate, and other micronutrients are responsible for a substantial proportion of malaria morbidity and mortality." They state that the attributable fraction of nutritional deficiencies to malaria attacks in children with malaria less than five years of age globally is 8.2 for those underweight ( $Z$ score $\leq 2), 20.1$ with zinc deficiency, and 20 with vitamin A deficiency; they ascribe the fraction of deaths in children less than five years 
old attributable to nutritional deficiencies as 57.3 for underweight children, 20.1 for those with zinc deficiency, and 19.5 for children with vitamin A deficiency. Caulfield and others recommend strongly, as do other contributors to this supplement, that good nutrition, micronutrient supplementation programs, and nutrition education be integrated fully into malaria prevention and control programs.

Important evidence is accruing of the long-term neurocognitive impact of malaria following severe illness. Mung'AlaOdera and others point out the many limitations in extracting such data from published studies and using demographic information to define this burden. They "estimate that at least 1,300-7,800 children will have neurologic sequelae following cerebral malaria in stable endemic areas per year in Africa. The figure is likely to be considerably higher, since these estimates do not include ... impairment following noncerebral malaria in children or adults ... or populations in low stable or epidemic areas." ${ }^{18}$ Of 11 well-defined neurocognitive sequelae following malaria (ataxia, hemiparesis/ monoparesis, severe motor deficit, dysphasia/dysarthria, behavioral difficulties, severe learning difficulties, visual impairment, hearing impairment, cognitive impairment, language impairment, and epilepsy), these investigators pay particular attention to the many economic costs of disabilities due to epilepsy and motor impairment and underscore that children with these sequelae are prone to an early death.

Holding and Kitsao-Wekulo review direct and indirect pathways whereby malaria can impede child development. ${ }^{19}$ They illuminate the considerable differences in methodology, cultural context, and validation of approaches for the few previous studies that address impaired child development following malaria. To overcome these differences, they suggest applying "The International Classification of Functioning, Disability and Health (ICF)" to such work, which covers in great detail the subtleties and degrees of motor, cognitive, behavioral, and other psychologic impairments that fall under childhood development. The ICF designated outcomes, with two-tiered division of impairment and activity limitation and participation restriction, provide the proposed take-off point for assessing past studies and designing new ones. With this in view, the investigators ask the important questions, "what should we be measuring and ... how should we be measuring it?"

\section{THE MALARIA BURDEN: ENTOMOLOGIC AND TRANSMISSION DYNAMICS}

Establishing the relationship between transmission intensity and health outcomes is crucial for the planning of longterm malaria control programs. Unfortunately, this is fraught with methodologic difficulties. Smith and others address some of these difficulties by considering important parameters that have been ignored previously. One important consideration is that one often finds the incidence of $P$. falciparum infection much lower than that predicted by the EIR, especially at higher transmission levels. ${ }^{20}$ Their report proposes an algorithm for estimating human infection rates from the EIR. Using the algorithm, Smith and others reanalyze EIR data and age-specific incidence of clinical malaria in two villages in Senegal, and assess a survey of infant and child mortality rates across Africa. The malaria transmission intensity in endemic areas with substantial mortality appears very different from those areas with acute morbidity. Infant mortality rates decrease markedly when the EIR is reduced, probably largely because of prevention of indirect mortality. This study also shows that reduction of exposure to malaria during infancy is not reflected in increased mortality at older ages, a concern of many who think that good childhood protection programs may predispose to later susceptibility.

Killeen and others posit that comprehensive environmental management of "mosquito resources" is a promising approach with which to control malaria but one that has seen little application in Africa for more than half a century. A kinetic model is presented of mosquito foraging for aquatic habitats and vertebrate hosts that allows estimation of malaria transmission intensity by defining the availability of these resources as the rate at which individual mosquitoes encounter and use them. ${ }^{21}$ The model captures historically observed responses of malaria transmission to environmental change, highlights important gaps in understanding vector ecology, and suggests solutions. Resource availability is an intuitive concept that provides an adaptable framework for models of mosquito population dynamics, gene flow, and pathogen transmission that can be defined with direct field measurements. The model predicts that drastic reductions of malaria transmission are possible with environmental management, and elucidates an ecologic basis for previous successes of integrated malaria control in Africa before the advent of DDT or chloroquine. Environmental management for malaria control requires specialist skills that are lacking in sub-Saharan Africa where they are needed most. Infrastructure and human capacity building in clinical, public health, and environmental disciplines should be prioritized so that the growing financial support for tackling malaria can be translated into truly integrated control programs.

McKenzie and Samba examine the lessons that can be drawn from mathematical models that have long provided important insights for malaria transmission and other infectious diseases. ${ }^{22}$ They cite the recent success of the Onchocerciasis Control Program in West Africa, and show that models can make great practical contributions to intervention programs if the modeling is well-integrated into the overall planning and if the participants are clear about what models can and cannot do. ${ }^{23}$ Their report argues that the models cannot provide exact predictions of outcomes: they can be used to forecast, but only in fairly gross terms. The biologic, social, and other systems involved are sufficiently complex such that it may not be possible to define all of the variables, much less get precise predictions about their interactions and confident results in a real-world situation. One must look for large differences between different models and between different interventions in the same modeling scenario. In sum, mathematical models can be used to 1) systematically compare alternate intervention strategies, 2) determine the key issues in decision-making, and 3) identify gaps in current knowledge.

Using carefully collected and analyzed data from the field, mathematical models can help focus on decisions which will have the largest impact on outcomes and provide comprehensive examination of the assumptions that enter into decisions in a way that purely verbal reasoning and debate cannot. Thus, models may make an important contribution to evidence-based malaria control. The malaria control project in 
Garki, Nigeria in the 1970s was a test of the mathematical models forwarded earlier by George McDonald. ${ }^{24,25}$

\section{MALARIA IN THE URBAN, EPIDEMIC, AND COMPLEX EMERGENCY SETTING}

Reviewing evidence from Kinshasa, the capital of the Democratic Republic of the Congo, Kazadi and others show an unprecedented increase in the prevalence of malaria in school age children from 1980 to $2000 .^{26}$ The city has been a perennial malarious area and has grown almost $1,400 \%$ over 43 years, from 380,000 people in 1960 to 5,293,000 in 2003. The most complete information on malaria prevalence in Kinshasa was first acquired from 1981 to 1983 . Blood smears were obtained from 25,135 children (age range $=5-15$ years) from 245 schools in 16 of 24 zones. The mean $P$. falciparum parasite rate (PR) was $17 \%$; the PR was similar for both sexes and was higher $(P<0.001)$ for older students. The PR varied from $4 \%$ in the urban zone to $46 \%$ in the peri-urban zone. An infant survey confirmed malaria transmission in the city because these children had not traveled out of Kinshasa since birth. During the Roll Back Malaria (RBM) partnership situational analysis in 2000, malaria prevalence was reassessed by the National Malaria Control Program and its partners in schools from selected health zones. A mean PR of 34\% was found among school children 5-9 years of age. The PR varied from $14 \%$ in the central urban zone to $65 \%$ in the peri-urban zone. Plasmodium falciparum was not the only species ( $P$. malariae was also present), but accounted for more than $97 \%$ of the infections. Malaria incidence has increased in Kinshasa during the last two decades due to difficulties in provision of control and prevention measures. Along with deployment of ITNs and improved patient management, currently ongoing, other measures that could impact the disease are being considered, including vector control, water management, and urban planning.

Caldas de Castro and others examine malaria and its control in the urban setting. The rapid growth of cities in subSaharan Africa (approximately $10 \%$ per year) is associated with complex transformations of these specialized ecosystems. Although urban malaria transmission is substantially less intense and more focal than in rural and peri-urban settings, the danger of epidemics can be higher due to the presence of non-immune populations. People of all ages are often at comparable levels of risk in urban settings. This report reviews the 100-year history of malaria control in Dar es Salaam, Tanzania, and describes and evaluates a control program supported by Japan that operated from 1988 to $1996 .^{27}$ The investigators conclude that because of the microepidemiology of malaria, urban risk-mapping methodology must include high-resolution aerial photography with groundbased validation; they contend that remote sensing technology at a level of resolution of one meter is essential for guiding intervention strategies for urban malaria control.

Keiser and others address urban malaria in general by reviewing the literature and using modeling. They found EIR in cities across Africa ranging from 0 to 54 per person per year; the EIR is dependent on the degree of urbanization, spatial location of populations within a city, and living conditions. ${ }^{28}$ Using the latest United Nations figures on urbanization, nighttime light, remotely sensed images, and the "Mapping
Malaria Risk in Africa" (MARA/ARMA) database, with its findings on climate suitability for stable malaria transmission, these investigators estimated that 200 million people $(24.6 \%$ of the total African population) currently live in urban settings where they are at risk of contracting the disease. ${ }^{29}$ This is cause for great concern in that the surface area covered by these urban settings is approximately $1.1-1.6 \%$ of the total African surface. Using different scenarios, Keiser and others estimate an annual incidence of 24.8-103.2 million cases of clinical malaria attacks among urban dwellers in Africa. These figures translate to $6-28 \%$ of the estimated global annual disease incidence. Mitigation of the current burden of malaria in urban African settings with visionary planning is necessary for environmentally and socially sustainable development. It appears that urban malaria control will be more cost-effective than in rural areas, and research is needed to confirm this.

Malaria epidemics have been on the increase during the last 10 years. Kiszewski and Teklehaimanot discuss this phenomenon, which results from special interactions between vectors, parasites, humans, and various environmental and anthropogenic determinants. ${ }^{30}$ Figure 4 shows particularly vulnerable areas of Africa against a background of different levels of endemicity. ${ }^{5,31}$ The explosiveness of malaria epidemics always strains the capacity of health facilities, causing case fatality rates to increase five-fold or more during outbreaks. People of all ages remain susceptible to the full range of clinical effects. The disease profile always has major economic consequences, although the full economic impact of

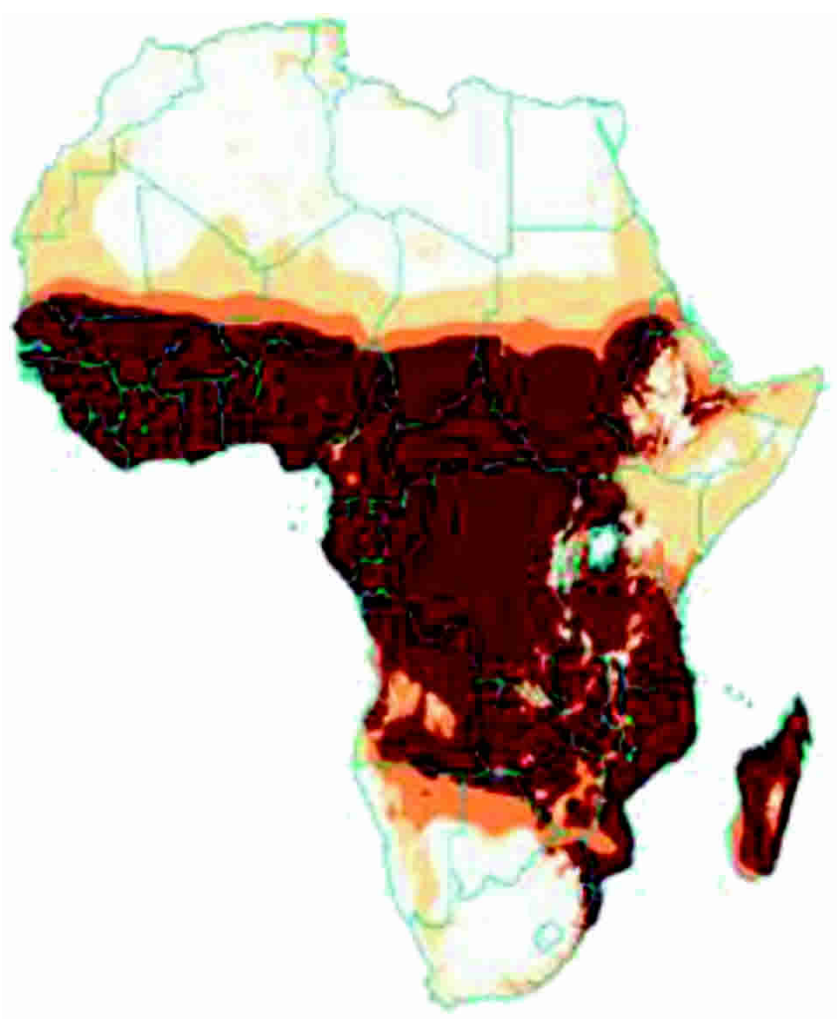

FIGURE 4. Malaria risk areas in Africa according to climate suitability ${ }^{5,31}$ White $=$ class 1 , no transmission; yellow $=$ class 2 , marginal risks, uncommon transmission in an average year; orange = class 3 , acute seasonal transmission with a tendency toward epidemics; brown $=$ class 4 , stable endemic transmission. 
epidemic malaria remains undefined. Specialized intervention approaches are needed for epidemic-prone areas, including enhanced surveillance activities and intensified antivector interventions. Such considerations are particularly critical at a time when malaria epidemics are occurring more frequently in Africa and throughout the world.

Worrall and others review malaria epidemics and the difficulties of estimating their economic burden. ${ }^{32}$ The main problems are the lack of a sound understanding of the epidemiologic toll and imprecision of the economic impact of malaria epidemics at all levels of the economy. There is no recent evidence from Africa on the macroeconomic impact of malaria epidemics. Examples are from the private sector and cover epidemics in the highland tea and coffee estates in east Africa; unfortunately, the impact on the companies' productivity, profitability, and growth remains unquantified. Work has begun to examine the cost of recent malaria epidemics in a sugar estate and orange plantation in Ethiopia (Ministry of Health of Ethiopia). In the public sector, epidemics may impose large political and opportunity costs on governments that often divert funds from other areas (usually within the health sector) to deal with large-scale epidemic emergencies. A 1996-1997 malaria epidemic in one district of Zimbabwe was estimated to add approximately $\$ 290,000$ to the direct costs of malaria control to the Ministry of Health alone, when compared with costs in the prior, non-epidemic year. Aside from this rough estimate, the direct and indirect costs which malaria epidemics impose on governments remain an important area for investigation.

\section{THE MALARIA BURDEN: ECONOMIC AND SOCIAL IMPACT}

Despite imprecisions, the malaria toll has been relatively well-quantified clinically and epidemiologically. In economic and social terms, it is less well understood. The channels by which disease lowers gross domestic product per capita is shown in Figure 5. ${ }^{33}$ Estimates have suggested that malaria costs the African countries $\$ 12$ billion annually and may considerably retard economic development. ${ }^{34}$ An African family may spend up to $25 \%$ of their income on malaria prevention and control. ${ }^{35}$ The economic burden of ill health on individual households can be substantial and in some cases catastrophic, especially for poor households. Russell reviews studies that have measured the economic costs and consequences of illness for households, focusing on malaria, tuberculosis and HIV/AIDS. ${ }^{36} \mathrm{He}$ finds that illness imposes high and regressive cost burdens on patients and their families in poor settings. Health service weaknesses contribute to these high costs in many countries, and include low coverage, user charges, and poor quality of care. Solutions lie in expanded access to high quality, carefully supervised preventive and curative health services.

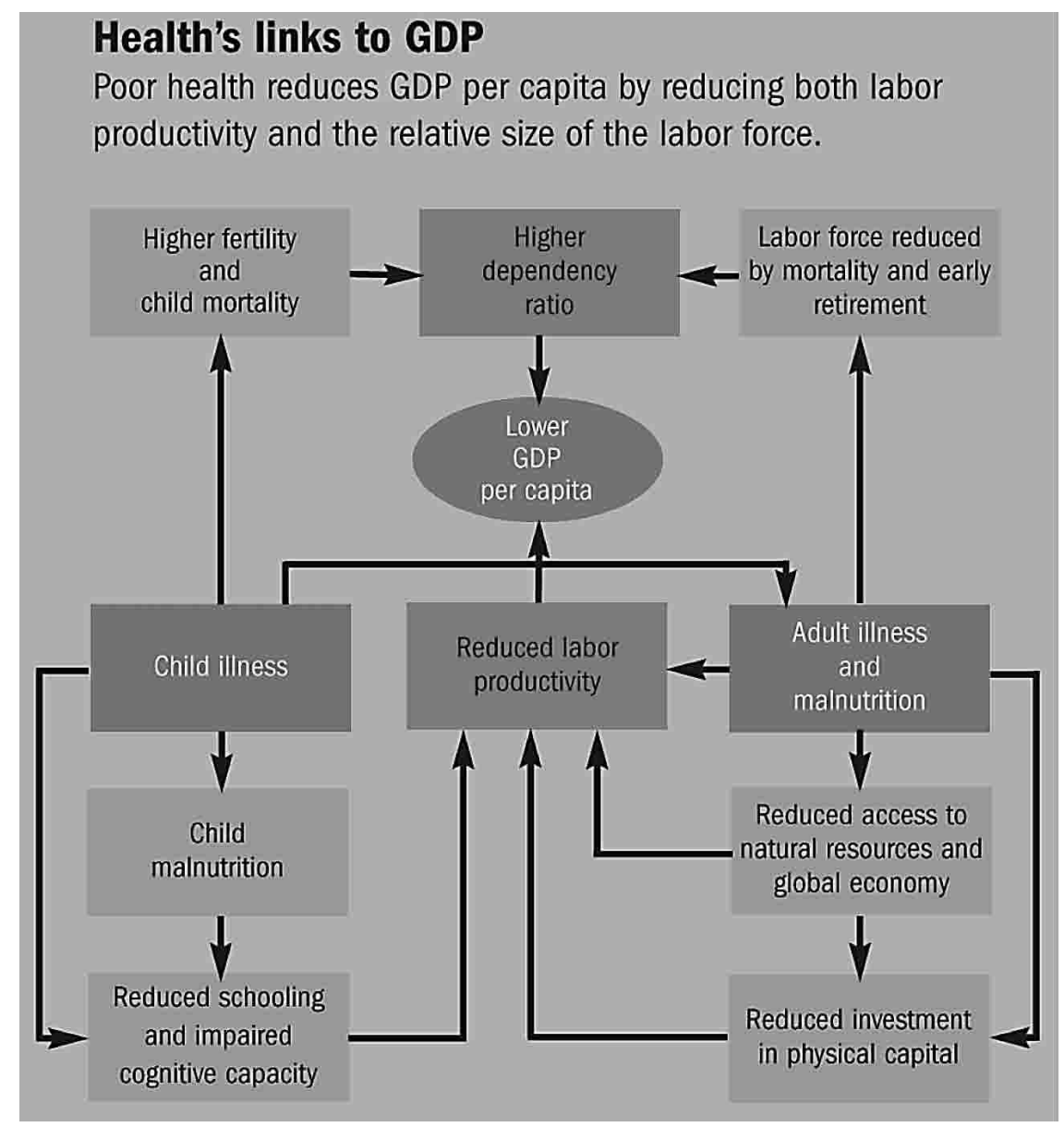

FIGURE 5. Impact of disease on lowering gross domestic product (GDP) per capita. ${ }^{33}$ 
Malaney and others state "although the correlation between malaria and poverty is apparent, the nature of the linkages in terms of directions and causation is less so, and different methodologic approaches provide widely divergent perspectives." 37 They review the evidence on both the macroeconomic and microeconomic impact and seek to explain why the former provides estimates of burden that are much greater than the latter. They argue that the economic externalities associated with malaria make the burden much greater than the sum of the costs of individual cases. For example, if malaria affects schooling decisions of households, then this could change long-term income streams in a much more marked fashion than would be expected from a caseby-case analysis of costs.

Jones and Williams point out that epidemiologists and economists have dominated the burden literature. They attest that culture, beliefs, and political context affect perceptions, individual behaviors, social structure, and social action. ${ }^{38}$ It is important to understand the social burden, or the process through which social and cultural factors affect the biomedical burden of malaria. Society's perceptions of disease, malaria, and perceived risk influence people's willingness to change their health behaviors, but the political and economic context, social organization, and cultural rules affect their ability to change behavior. Recently, the concept of social vulnerability has been developed to highlight the importance of social factors that make some groups or individuals more susceptible to infection or more vulnerable to the consequences of infection. For example, women may be limited in their access to cash and ability to take decisions on their own, affecting their ability to seek treatment of a sick child. The investigators argue that understanding the sociocultural dimensions of the burden of malaria is vital to development of interventions to access vulnerable groups.

\section{HEALTH SYSTEMS AND THE MALARIA BURDEN}

Health management information systems (HMIS) including routine surveillance systems at health facilities provide the immediately visible evidence of the burden of malaria, which is the basis for planning. Most malaria-related morbidity is treated at home and within the community by informal health services and networks. Ageypong and Kangeya-Kayondo use a case study from a rural district in Ghana to illustrate the wide difference between estimates of the burden of "febrile illness presumed malaria" based on routine HMIS data, and that derived from community level data on morbidity and health seeking behavior of households. ${ }^{39}$ For every patient with febrile illness seen in facilities, there were 4-5 such episodes in the community. Given the urgency of changing drug use policies in Africa, and exploring associated costs and logistics, it is urgent that better and more timely data on burden be available to health service planners. The report by Agyepong and Kengeya-Kayondo highlights the current practices of treatment-seeking families, indicating how much selftreatment through purchase of drugs occurs. These practices, widespread in most malarious countries, raise questions on what should be the appropriate policy response.

Who should pay for malaria interventions? Hanson outlines how the tools of economic analysis can contribute to such discussions. She argues that there are powerful economic arguments to support public action to increase the uptake of effective malaria interventions. ${ }^{40}$ Market failures are likely to arise from the monopoly power of pharmaceutical firms. Another important form of market failure arises from "externalities," which are benefits or costs of consumption or production that are not fully valued by the consumer/producer. As a result, the level of consumption is often not optimal. Externalities affect, for example, availability and deployment of ITNs, residual insecticide house spraying, environmental control, and, potentially, artemisinin-based combination therapy (ACT). Commercial markets are unlikely to guarantee adequate uptake of interventions where there is widespread poverty. Limited public resources mean that prioritization is necessary. Economic analyses help decision making by setting priorities through cost-effectiveness analyses, understanding how markets for interventions operate, and the extent to which different approaches reach the poor, the prime target of public actions.

A recent and very important theme in research and policy debates has been the impact of malaria on different socioeconomic groups and the extent to which the poor are reached by interventions. Barat and others report that malaria disproportionately affects poor countries, with $58 \%$ of the cases occurring in the poorest $20 \%$ of the world's population. ${ }^{41}$ Within countries, there is contradictory evidence on whether the poorest experience more febrile episodes, and quite strong evidence that the severe consequences of malaria are borne most heavily by the poorest citizens. These investigators call for more research on financial and non-financial factors that limit the accessibility and use of malaria control services by the poorest, who remain the most vulnerable persons.

\section{INTERVENTIONS: ACT}

While CQ and sulfadoxine-pyrimethamine (SP), are becoming increasingly ineffective throughout the world, most recently in Africa, they are still being used, particularly in western Africa. Yeung and others advocate the use of ACT "for delaying the development of resistance to the remaining armory of effective drugs." 42 Combination drug strategy is used for tuberculosis, HIV infection, and cancers. The investigators outline the difficulties in measuring the burden due to parasite resistance to drugs and in defining the impact of control strategies. They use a mathematical model to address these and other issues tied to policy options in the face of drug resistance. A major impediment to using ACT is its cost, currently $\$ 1.20-2.50$ per adult treatment compared with $\$ 0.10-0.20$ per adult treatment for CQ and SP. The costeffectiveness model presented by the investigators uses biologic and economic information. They assume that the demise of CQ has contributed directly to the doubling of malariaspecific mortality over the last 15 years. ${ }^{43}$ The investigators urge that patients in drug-resistance studies be followed for 28 days rather than 7 or 14 days as recommended by the WHO. This should now be easier with the availability of parasite genotyping, allowing researchers to distinguish between recrudescence and reinfection. The genetic basis of resistance is described fully by these investigators who state "for resistance to spread the spontaneous occurrence of a mutation ... is not sufficient". Drug pressure is necessary to confer survival advantage of resistant parasites. To date, resistance to artemisinins has not been documented. 
Using ACT, preventing spread of resistant parasites optimally requires a three-day treatment; monotherapy with artemisin compounds requires seven days of treatment. Drugs with a long half-life allow longer parasitic exposure to subtherapeutic drug levels. Under these conditions, drug resistance mutations are more likely to develop and spread. Yeung and others make a strong plea for accurate diagnosis before treatment, using rapid diagnostic tests. ${ }^{42}$ They admit that these tests are costly ( $\$ 0.70$ per test) and likely to be most cost-effective when more than $50 \%$ of the patient population is parasitemic; these dip-stick enzymatic tests have other advantages and disadvantages when compared with microscopy. ${ }^{44}$ Artemether-lumefantrine (Coartem ${ }^{\circledR}$; Novartis, Basel, Switzerland) is the only registered ACT; however, dihydroartemisinin-piperaquine (Artekin ${ }^{\circledR}$; Chongqing Holley Holding, Chongqing, People's Republic of China) has been found to be safe, effective, and acceptable, and is cheaper than Coartem ${ }^{\circledR}$. Although Artekin ${ }^{\circledR}$ is used extensively in Cambodia, China, and Vietnam, this drug has not yet gone through the lengthy regulatory process required for international use. The model used by these investigators incorporates drug, epidemiologic, parasitologic, vectorial, behavioral, and economic factors. It is a time-intensive model in which drug resistance develops in two stages: de novo and with subsequent spread. Studies have shown that patients with mefloquine-resistant parasites carried gametocytes four times longer than those with sensitive parasites. ${ }^{45}$ A relative reproductive rate of four for resistant infections is used in the model. The increasing cost of drugs with increasing drug resistance and other costs, e.g., consultation, diagnosis, inpatient care, and specific complications (anemia, cerebral malaria, renal failure, and low-birth weight babies) are considered in the model as are transport, food, medicines, and loss of productivity.

Laxminaryan also uses a bioeconomic model of malaria and evolution of drug resistance to examine ACT and the economics of dealing with drug resistance. ${ }^{46}$ His focus is on the economic evaluation of alternatives to use of CQ. Sulfadoxine-pyrimethamine has the advantage of requiring one dose, costs approximately one-tenth as much as ACT, and is approved for use in children and pregnant women; the disadvantage is that parasite resistance to SP is expected to increase. The use of ACT will delay resistance and offer faster and higher cure rates than other drugs. Laxminaryan models replacement of CQ with 1) ACT and 2) SP with waiting for resistance to develop before using ACT; optimal coverage is also considered. He echoes Yeung and others in stating that "resistant strains face an evolutionary disadvantage in the absence of antimalarials." Both Laxminaryan and Yeung and others posit that effective treatment is associated with loss of immunity, but there is little evidence for loss of protective immunity after treatment in the African milieu. It is true that the use of ACT or other effective treatments will reduce the number of parasites in circulation by reducing the duration of illness.

One artemisin model is based on the questionable assumption of Laxminarayan that malaria-specific mortality would be zero. This needs further elaboration, despite the statement that "introducing an appropriate case fatality rate did not alter the results relatively." Laxminarayan concludes that, in the short run, SP may be preferable at low and high levels of coverage and low selection pressure. However, at high levels of treatment coverage, resistance will evolve rapidly. For long-range planning, a direct switch to ACT is desirable given the high morbidity associated with increasing resistance to SP. The contention that "with higher intensity of transmission, the benefit ... of ACTs ... is diminished because of greater immunity associated with transmission ..." remains to be proven. The model shows that the economic advantages of introducing ACT immediately are lower for situations with high frequencies of resistance to either drug in the ACT. In addition, patients taking three doses of ACT will be less adherent to taking the complete treatment than those taking one dose of SP, which could theoretically expedite resistance to the components of the ACT.

Coleman and others use a decision-tree model to estimate the incremental cost-effectiveness of using ACTs, compared with current therapies over 5-, 10-, and 15-year periods. ${ }^{47}$ Defining the growth rate of ACT resistance to other drugs allows calculations of the threshold ratio at which ACT is no longer cost-effective, compared with any levels of resistance to current therapies including the starting levels of resistance following monotherapy. By their model, these investigators show that ACT is more than $95 \%$ likely to be cost-effective over any time period under most conditions other than with very low levels of initial resistance to $C Q$, and over a five-year time frame. They focus on 1) the growth rate of resistance of ACT relative to monotherapy, and 2) the starting level of resistance of the monotherapy. Comparisons are made of the cost-effectiveness of ACT relative to a baseline scenario of retaining SP over a set time period. The investigators restrict the analysis to true malaria and weight the population by the proportion $<5$ years of age and $\geq 5$ years of age. As for the other models, compliance is a major factor in the analysis as is proportion of resistant parasites and probability that the treatment is effective with partial compliance. The model allows DALYs and costs to be calculated. Policy change costs, which can be substantial, are not factored into this model, or in the others. The incremental cost-effectiveness ratio is compared with a cut-off value of $\$ 150$ per DALY averted, "a rough economic criterion by which a health intervention in a developing country may be judged ... attractive." Above $60 \%$ resistance to SP, ACT is cost-effective for a 10 -year period. The investigators present a very elegant analysis of the economic effectiveness of ACT over different time periods, and different levels of drug resistance. The advantages of ACT over SP, with the latter drug having 20-60\% resistance, are highlighted depending on the time frame $(5,10$, or 15 years). These investigators conclude rightfully that "given current limited production of ACTs, ... logistical support must be in place to ensure that ACT is widely available before advocating a switch in policy."

One important economic assumption regarding ACT use is that direct costs such as drugs, consultations, and laboratory testing amount to approximately $20 \%$ of the costs, with opportunity costs of travel and loss of productive time, totaling 1-5 days per patient, comprising $80 \%$ of the costs. For example, a study in four African countries (Burkina Faso, Chad, Republic of the Congo [Brazzaville], and Rwanda) found that a case of malaria costs $\$ 9.83$ (in 1987 dollars) of which $19 \%$ was direct costs (treatment and control) and $81 \%$ indirect costs (morbidity, mortality and economic losses). ${ }^{48}$ Since the average value of goods and services produced per day in Africa was $\$ 0.82$, this cost was equivalent to 12 days of output. 
Although the costs of drugs are only a small percentage of the economic cost of a malaria episode, the likely increased use of ACT will lead to major expenditures. Between $\$ 1.6$ and \$3.4 billion per year will be required for African countries to have malaria treatment policies based on ACT. ${ }^{49}$

\section{INTERVENTIONS: MONITORING, EFFECTIVENESS, AND COST-EFFECTIVENESS}

For disease control, the balance between an interventionspecific approach and a broad health services approach has been debated over many decades, with the pendulum swinging from one period to another. Following the failure of vertical malaria control programs to achieve eradication during the 1960s and 1970s, the World Health Assembly in 1985 adopted a resolution recommending that malaria control activities be developed as an integral part of primary health care systems at the district level. Alilio and others assess the extent to which primary health care services contributed to reducing the burden of malaria in one district in Tanzania between 1996 and 2003. They find an unchanged malaria burden since the 1960s and limited effectiveness of district health services in controlling malaria. ${ }^{50}$ Although there had been a process of decentralization, the district management had weak capacity to develop and implement local policies and received little training on malaria control; organizational and other changes did not result in better operational decisions, improved access to treatment, or fewer malaria cases and deaths. The investigators recommend that a combination of central (national) and local action is required for effective malaria control, and that activities at the district level require better coordination and definition. The evaluation of effectiveness of district actions using longitudinal data and an in-depth case study approach is advised.

An alternative methodologic approach is taken by Over and others in analyzing the contribution of a mix of interventions to malaria control in the Solomon Islands from 1993 to 1999. ${ }^{51}$ To determine the contribution of each method, data were analyzed by monthly incidence and by assessing control activities for 41 of 110 malaria zones. The analysis found that spraying with DDT, use of ITNs, and education on malaria were all independently associated with reduction in malaria or fever incidence, while larviciding with temephos was not. The use of treated nets permitted a reduction in DDT spraying, but would not replace it without substantially increased malaria incidence.

de Savigny and Binka examine problems in measuring the impact of the malaria burden in sub-Saharan Africa. They argue that ambitious new goals for control of malaria have been set and significant additional resources for malaria control are being mobilized. Yet, for many of the countries most severely burdened by malaria, baseline data and reliable monitoring of key impact indicators are lacking. ${ }^{52}$ For such countries, it will be difficult to know when targets are met or whether to make mid-course corrections if progress is inadequate. The new investments in malaria control have triggered a resurgence in the demand for health information for assessment of performance-based resource allocation. Activity (process) and health impact (outcome) indicators need to be defined early, with clear goals and milestones to track local, national, and international achievements. ${ }^{53}$ It is essen- tial to support more integrated information systems able to monitor change and guide approaches, not just for malaria, but for other important health and poverty-related interventions. The investigators urge re-thinking the nature of the data and the sources feeding into the management information systems in resource-poor settings. They suggest a pathway that helps create effective monitoring and evaluation systems in a framework for longitudinal, iterative, and evidencebased decision making. Health information systems of the future will need much greater coherence in using information from disparate sources and much greater ability to influence punctual actions in the field.

Monasch and others add to the issues raised in the report by de Savigny and Binka by examining childhood coverage with mosquito nets and malaria treatment. This report, based on population-based surveys in African countries, provides a useful baseline for monitoring progress in the RBM partnership. Data are reviewed from 23 Multiple Indicator Cluster Surveys and 12 demographic and health surveys (DHS) conducted between 1998 and 2002. ${ }^{54}$ The investigators examine the proportion of febrile children less than five years of age with prompt effective antimalarial treatment and the proportion of those less than five years old sleeping under ITNs or any mosquito net the preceding night. A median of $53 \%$ of the febrile children received antimalarial treatment; a median of $84 \%$ of these treatments used CQ. The proportion of treatments given within two days of onset of symptoms was unknown in most surveys. Median coverages of those less than five years old with any net and with ITNs was $15 \%$ and $2 \%$, respectively. Use of nets, and especially ITNs, was consistently lower in rural than in urban areas. At the outset of intensified malaria control under the RBM partnership, coverage with principal interventions was minuscule, far below the target of $60 \%$ set for Africa in 2005. Much remains to be done to improve effective coverage for effective treatment of and protection from malaria. Measuring change accurately and frequently, and taking action, is a challenge of great urgency and magnitude and merits the highest priority.

\section{WHAT'S NEEDED: RESEARCH, TRAINING, AND CONNECTIVITY}

Great progress has been made in development of vaccines for malaria. Ballou and others report that there are now 35 candidate malaria vaccines in clinical development, many of which are, or soon to be in clinical trials. ${ }^{55}$ Of these, the pre-erythrocytic vaccines that target sporozoites or schizontinfected liver cells, preventing the release of primary merozoites from infected hepatocytes, have received the most attention; 16 candidate vaccines are in this group. While only a $100 \%$ protective response translates into sterile immunity for a vaccine directed against this stage of the parasite, responses that are $80-90 \%$ effective may delay onset of patent parasitemia and elicit an eight-fold reduction in circulating infectious sporozoites. These investigators report that the RTS, S/AS02A vaccine, based on the circumsporozite protein of the 3D7 clone of $P$. falciparum, showed some protection in humans over two transmission seasons, including reduction of febrile malaria attacks. It is crucial to formulate the vaccine with the proprietary adjuvant AS02A. The formulation stimulates Th-1 cellular immune responses, which were shown to 
be important in clinical trials. The protective immunity conferred by this vaccine wanes over time. The RTS, S/AS02A vaccine development and testing is an excellent example of private-foundation-public partnership, in that Glaxo-SmithKline Bio, the Malaria Vaccine Initiative (supported by the Bill \& Melinda Gates Foundation), and governments in Gambia, Mozambique, and elsewhere are partners in its testing.

The target for the 15 candidate asexual stage vaccines is the merozoite, initially released from infected hepatocytes, which rapidly enter circulating red blood cells. The complex process of merozoite invasion of red blood cells requires contact, adherence, and orientation to the cell-wall membrane, and involves numerous parasite proteins located on the surface of the merozoite and targeted by circulating antibodies. Merozoite surface protein 1 (MSP-1), MSP-2, MSP-3, and apical menbrane antigen 1 are the most studied asexual stage vaccine antigens. Although antibodies directed against the parasite are essential, cell-mediated mechanisms are critical for acquired immunity. Variability in parasite genetic composition is a major hurdle in development of blood-stage vaccines. Production of antibodies against the carboxy-terminal portion of MSP-1 has been achieved and the antigen adjuvantized as falciparum merozoite protein-1/AS02A. A trial of this vaccine in children is scheduled in western Kenya.

Antibodies directed against several sexual parasite stage antigens can prevent infectious sporozoite development in the salivary glands of Anopheles mosquitoes. These transmissionblocking vaccines (TBVs) have received much-deserved increased attention over the past 10 years and two antigens are in development. The TBVs do not protect individuals receiving them from malaria infections. High coverage with an effective vaccine will be needed to stop malaria transmission. This is why TBVs are called the "altruistic" vaccines. Sexual stage antigens have proven to be complex proteins with complex folding requirements and formulation of immunogenic vaccines remains a challenge. Plasmodium vivax antigen Pvs25 produced in Saccharomyces cerevisiae elicits antibodies in mice, rabbits, and non-human primates and blocks transmission in membrane feeding assays. Plasmodium falciparum antigen Pfs25 expressed in Pichia pastoris appears promising. Another very intriguing approach is to irradiate large numbers of sporozoites, effectively producing a killed parasite asexual-stage vaccine. This revisiting of work begun 30 years ago merits increased attention. ${ }^{56}$

The key to success in malaria vaccine development will be increased funding and support by public-private partnerships, particularly for production of test lot vaccines by good manufacturing procedures and conducting phase 1 and 2 studies. It is very encouraging that RTS, S/AS02A, modified vaccine Ankara-multi-epitope thrombospondin-related adhesive protein (MVA-ME TRAP), and MSP-1/AS02A vaccines are now being tested in pediatric populations in malarious settings, the most vulnerable group. One of the greatest needs that is sure to increase over the next several years is for more qualified clinical investigators in malaria-endemic and nonendemic countries to carry out the vaccine studies.

The major decisions for introducing malaria vaccines and other new or improved interventions to control malaria into a country will be made by national policy makers. These persons must use the results of research wisely to minimize delays and get the most benefit once a malaria vaccine is ready for use. Moree and Ewart review the factors to consider for rational decision-making when introducing a malaria vaccine. ${ }^{57}$ These are disease burden, economic burden, costeffectiveness of existing anti-malaria interventions, financing plans, delivery and infrastructure systems, and the selection of specific new vaccines, malaria and otherwise. Key decisions will depend upon a vaccine's ability to reduce morbidity and mortality and competing demands for funding. To illustrate the decision-making process, these investigators assume a $30-50 \%$ vaccine efficacy for one year in preventing severe disease in children 1-4 years of age, with three doses required at $\$ 10$ per dose. They cite hepatitis B and Haemophilus influenzae type $\mathrm{B}$ experiences to illustrate how long delays in vaccine deployment can occur despite proven efficacy, particularly in low-income countries. Modeling can be useful to inform vaccine outcomes, particularly when surveillance is poor. AMANET, formerly the African Malaria Vaccine Testing Network (AMVTN), has promoted the collection of epidemiologic data on malaria to support vaccine trials. Demographic and Surveillance Surveys are tracking malaria and other diseases over a longer period in large populations as is the International Network of Field Sites With Continuous Demographic Evaluation of Populations and their Health in Developing Countries (INDEPTH) and other DHS activities. Major constraints to timely introduction of a malaria vaccine could be the regulatory process. Regulatory reviews, important as they are, cost time and money and affect manufacturing and delivery of a sorely needed intervention. Operations research should focus on demographic and epidemiologic information and include accurate measurement of the disease and economic burdens, and cost-effectiveness of interventions, using modeling.

Despite the urgent need, Ijumba and Kitua attest that “... there are still no significant initiatives for strengthening capacity for malaria control through training within the African continent. . . " 58 In Tanzania, where these investigators live and work, the Center for Enhancement of Effective Malaria Interventions (CEEMI) has been established. The CEEMI will help "to provide ... skills for identifying and solving problems and providing incentives to malaria control workers in their work performance." Their report describes the workforce needs to achieve the goals of RBM, the main goal being decreasing the burden of disease by 2010. They state that "the targets will not be met until governments honor their (Abuja) pledges, sufficient funds are generated at the global level and ... activities at district, country, and regional levels are strengthened sufficiently. ..." Impediments to proper use of human resources are shortage of skilled workers, misuse of time, poor mentoring, lack of focus on specific problems, and diversion of malaria control staff to other health issues. Current training is centered on easy advancement and personal gain rather than on capacity strengthening. It produces certificate holders, not committed leaders or implementers. The CEEMI is part of the Gates Malaria Partnership that links the London School of Hygiene and Tropical Medicine with two northern and five southern partners in four malaria-endemic countries (Gambia, Ghana, Malawi, and Tanzania). The partnership roles are "to strengthen research capabilities and augment existing capacity through establishment of training centers in Africanpartner countries ..." and "for transferring knowledge (and) strategies related to (putting) malaria control into action." The investigators stress the importance of defining training 
needs, goals, strategies and actions, and monitoring and evaluation; the latter is a greatly neglected area. They envision the CEEMI as a place to support innovations for training, and will include training in the conduct of operational research, evaluation, and documentation.

A novel approach at CEEMI is that the candidates will define their work plan with local health and administrative officials before they come for training. In this way, the training modules can be tailored to the specific needs of the trainees and their districts. The major components of the Tanzanian National Malaria Control Program are case management, vector control with ITNs, prevention of malaria in pregnancy, and epidemic preparedness and prevention. It is expected that similar approaches in the Gambia, Ghana, and Malawi will allow mutually beneficial feedback through frequent exchanges of curricula, participants, teachers, and shared evaluations. An early workshop sponsored by CEEMI focused on ethics, information retrieval from the Internet, and traditional malariology. An e-mail discussion group was established to ensure that dialogue between participants and trainers continues long after the course completion.

Improved communication and coordination with colleagues by African scientists working on malaria has been the mission of the Multilateral Initiative on Malaria Communications Project (MIMCom). Royall and others report that over the past seven years MIMCom has supported full access to the Internet and resources of the World Wide Web at 19 research sites in 10 countries. $^{59}$ MIMCom has two websites: one is linked to resources, databases, and a document delivery service for full-text journal articles; another site is research agenda-specific, with a server capable of sharing data between members of MIM networks concentrating on a specific research theme. The key to the success of this very original activity has been the fact it was conceived by African researchers and, with them, designed, implemented, and monitored closely by the U.S. National Library of Medicine (NLM). Support from a variety of national and international collaborators, with expertise in information technology, satellite access, data management, local telecommunications, local regulations, and financial stability has been the sine qua non of MIMCom. The project focused first on taking advantage of the NLM decision to make MEDLINE ${ }^{\circledR}$ available free to the networked world in 1997, the time MIM began. The key question asked by MIMCom of the African scientists was "what is it that researchers are trying to accomplish but can't, given current telecommunications access?" The focus is entirely on local needs and priorities, cost-effectiveness, and local responsibility. An evaluation team focuses on local telecommunications availability to gain access to the World Wide Web, sending e-mail and large data files, and downloading large documents. When not available and needed locally, MIMCom uses satellite, microwave, or other wireless options. This includes a Very Small Aperture Terminal (VSAT) system in Kenya using a technical hub in the United Kingdom linked to a geostationary communications satellite 22,000 miles above the Atlantic Ocean. As new research stations have joined the VSAT system, costs are decreased by group purchases. Another special feature of MIMCom is that the equipment supplier has provided a unique bandwidth shared by more than 1,000 scientists and their support teams. At each site, there is a List Server, Help Desk, Intranet, written usage policy with tools to monitor usage, and tools to block unre- lated websites. These innovations promote creative local problem solving and conserve valuable telecommunications resources.

MIMCom has held a series of meetings to share research and telecommunications activities and experiences with network numbers. During these exchanges researchers from different countries and sites developed a memorandum of understanding covering their collaboration, data sharing, database security, publication policies, development of a website, and defined the responsibilities of each investigator for the website pages. The shared funding of the project locally helps to ensure sustainability and ownership by a larger number of parties rather than the fragility created when only one donor or northern scientific laboratory carries the entire project. The comment by one African colleague about the benefit of MIMCom is revealing "... we (now) run projects in Africa, we forward mail to each other, we plan and agree and disagree. It is not one man writing a letter (to us), giving instructions. There is a difference here. It is a completely different way of communicating."

\section{CONQUERING MALARIA: INTERNATIONAL ACTIONS}

International action in malaria research and control has a long history. Alilio and others identify three decades of great optimism after 1949. Successes in largely temperate or subtropical areas occurred where transmission was unstable and engendered undue expectations for malaria control elsewhere. Unfortunately, early successes led to substantially decreased support for research; on the control side, the disillusionment that followed the failure of eradication was followed by several decades of neglect of malaria in international health policy debates. ${ }^{60}$ These investigators review this history of multilateral malaria research and control programs in Africa to discern lessons to inform multilateralism and demonstrate the need to link research and control closely. Although the proliferation of malaria control programs in the late 1990s has brought substantial additional funds and expertise, it raises considerable concerns over duplication and coordination. They propose an umbrella malaria coordinating group to ensure inclusiveness, sharing of agendas, goals, and achievements, and increase advocacy for malaria research and control.

The MIM represents one of the most successful recent malaria initiatives; it has an explicit networking aim through linking and supporting organizations and individuals concerned with malaria research. It focuses on maximizing the impact of scientific research on malaria control in Africa through the promotion of research capacity building and facilitation of global collaboration and coordination. Heddini and others review the experience of MIM since it was created in 1997, and comment on its current components, activities, and future challenges. Their report underscores the importance of the MIM Alliance as a coordinating device, and emphasizes the need to retain research capacity strengthening as its prime focus. ${ }^{61}$ The research grant component of MIM has awarded funds to more than 23 African scientific groups. The scientists collaborate with a northern institution and, where possible, with one or more other African institutions. The Tropical Disease Research Program of WHO manages this 
component of MIM. The Malaria Research and Reference Reagent Resource Center (MR4), supported by NIAID, collects and distributes biologic materials for malaria research and does training. The MIM will continue to expand its focus, with more consideration of $P$. vivax and malaria in Asia and the Americas and strengthening of the research and control interface.

Acknowledgments: We thank Alexander Rowe, Richard Steketee, and Robert Snow for their valuable comments and Cherice Holloway for manuscript preparation.

Author's addresses: Joel G. Breman, Disease Control Priorities in Developing Countries Project, Fogarty International Center, National Institutes of Health, Building 16, Room 214, 16 Center Drive, MSC 6705, Bethesda, MD 20892-6705, Telephone: 301-496-0815, Fax: 301-496-8496, E-mail: jbreman@nih.gov. Martin S. Alilio, NetMark, Global Health, Population and Nutrition Department, Academy for Educational Development, 1825 Connecticut Avenue, NW, Washington, DC 20009-5721, Telephone: 202-884-8968, E-mail: Malilio@ aed.org. Anne Mills, Department of Health Economics and Policy, London School of Hygiene and Tropical Medicine, Keppel Street, London WC1E 7HT, United Kingdom, Telephone: 44-207-927-2815, E-mail: Anne.Mills@1shtm.ac.uk.

Reprint requests: Joel G. Breman, Disease Control Priorities in Developing Countries Project, Fogarty International Center, National Institutes of Health, Building 16, Room 214, 16 Center Drive, MSC 6705, Bethesda, MD 20892-6705, Telephone: 301-496-0815, Fax: 301496-8496, E-mail: jbreman@nih.gov.

\section{REFERENCES}

1. Yamey G, 2000. African heads of state promise action against malaria. BMJ 320: 1228.

2. Breman JG, ed, 2001. The intolerable burden of malaria: a new look at the numbers. Am J Trop Med Hyg 64 (Suppl 1-2): $1-106$.

3. Jamison DT, 2002. Cost-effectiveness analysis: concept and applications. Oxford Textbook of Public Health Volume 4, Detels R, McEwen J, Beaglehole R, Tanaka H, eds. Oxford, United Kingdom: Oxford University Press, 903-919.

4. Breman JG, 2001. The ears of the hippopotamus: manifestations, determinants and estimates of the malaria burden. Am J Trop Med Hyg 64 (Suppl 1-2): 1-11.

5. Snow RW, Craig MH, Newton CRJC, Steketee RW, 2003. The Public Health Burden of Plasmodium falciparum Malaria in Africa: Deriving the Numbers. Working Paper No. 11. Disease Control Priorities Project, Bethesda, MD: Fogarty International Center, National Institutes of Health, August 2003.

6. Murphy SC, Breman JG, 2001. Gaps in the childhood malaria burden in Africa: cerebral malaria, neurologic sequelae, anemia, respiratory distress, hypoglycemia and complications of pregnancy. Am J Trop Med Hyg 64 (Suppl 1-2): 57-67.

7. World Health Organization, 2002. Annex Table 3: Burden of disease in DALYs by cause, sex and mortality stratum in WHO regions, estimates for 2001. World Health Report, 2002: Reducing Risks, Promoting Healthy Life. Geneva: World Health Organization, 192-197.

8. Hay SI, Guerra CA, Tatem AJ, Noor AM, Snow RW, 2004. The global distribution and population at risk of malaria: past, present and future. Lancet Infect Dis 4: 327-336.

9. Marsh K, Foster P, Wariuru C, Mwangi I, Winstanley M, Marsh V, Newton C, Pasvol G, Snow R, 1995. Indicators of lifethreatening malaria in African children. $N$ Engl J Med. 332: $1399-1404$

10. Samba E, 2004. Bringing research, training and service delivery together to reduce the malaria burden in Africa. Am J Trop Med Hyg 71 (Suppl 2): iii-iv.

11. Ntoumi F, Djimdé A, Mbacham W, Egwang T, 2004. The importance and future of malaria research in Africa. Am J Trop Med Hyg 71 (Suppl 2): v-vii.

12. Snow RW, Korenromp E, Drakely C, Gouws E, 2004. Pediatric mortality in Africa: Plasmodium falciparum malaria as a cause or risk? Am J Trop Med Hyg 71 (Suppl 2): 16-24.

13. Lackritz EM, Campbell CC, Ruebush TK II, Hightower AW, Wakube W, Steketee RW, Were JB, 1992. Effect of blood transfusions on survival among children in a Kenyan hospital. Lancet 340: 524-528.

14. Crawley J, 2004. Burden of clinical management and anemia in African children. Am J Trop Med Hyg 71 (Suppl 2): 25-34.

15. van Geertruyden JP, Thomas F, Erhart A, D'Alessandro U, 2004. Malaria as an independent risk factor for perinatal mortality and/or stillbirths: a review and meta-analysis. Am J Trop Med Hyg 71 (Suppl 2): 35-40.

16. ter Kuile F, Parise M, Verhoef F, Udhayakumar V, Newman RD, van Eijk AM, Rogerson SJ, Steketee RW, 2004. The burden of co-infection with human immunodeficiency virus type 1 and malaria in pregnant women in sub-Saharan Africa. Am J Trop Med Hyg 71 (Suppl 2): 41-54.

17. Caulfield L, Richard SA, Black R, 2004. Undernutrition as an underlying cause of malaria morbidity and mortality. Am J Trop Med Hyg 71 (Suppl 2): 55-63.

18. Mung'ala-Odera V, Snow RW, Newton C, 2004. The burden of the neurocognitive impairment associated with Plasmodium falciparum malaria in sub-Saharan Africa. Am J Trop Med Hyg 71 (Suppl 2): 64-70.

19. Holding P, Kitsao-Wekulo PK, 2004. New perspectives on the causes and potential costs of malaria: The growth and development of children: What should we be measuring and how should we be measuring it? Am J Trop Med Hyg 71 (Suppl 2): 71-79.

20. Smith T, Killeen G, Lengeler C, Tanner M, 2004. Relationship between the outcome of Plasmodium falciparum infection and the intensity of transmission in Africa. Am J Trop Med Hyg 71 (Suppl 2): 80-86.

21. Killeen G, Seyoum A, Knols B, 2004. Rationalizing historical successes of malaria control in Africa in terms of mosquito resource availability management. Am J Trop Med Hyg 71 (Suppl 2): 87-93.

22. McKenzie FE, Samba E, 2004. The role of mathematical modeling in evidence-based malaria control. Am J Trop Med Hyg 71 (Suppl 2): 94-96.

23. Richards FO Jr, Boatin B, Sauerbrey M, Seketeli A, 2001. Control of onochocerciasis today: status and challenges. Trends Parasitol 17: 558-563.

24. Molineaux L, Gramiccia G, 1980. The Garki Project; Research on the Epidemiology and Control of Malaria in the Sudan Savanna of West Africa. Geneva, World Health Organization.

25. MacDonald G, 1957. The Epidemiology and Control of Malaria. Oxford, United Kingdom: Oxford University Press.

26. Kazadi W, Sexton JD, Bigonsa M, W'Okanga B, Way M, 2004. Malaria in primary school children and infants in Kinshasa, Democratic Republic of the Congo. Am J Trop Med Hyg 71 (Suppl 2): 97-102.

27. Caldas de Castro M, Yamagat Y, Mtasiwa D, Tanner M, Utzinger J, Keiser J, Singer BH, 2004. Integrated urban malaria control: a case study in Dar es Salaam, Tanzania. Am J Trop Med Hyg 71 (Suppl 2): 103-117.

28. Keiser J, Utzinger J, Caldas de Castro M, Smith TA, Tanner M, Singer BH, 2004. Urbanization in sub-Saharan Africa and malaria control. Am J Trop Med Hyg 71 (Suppl 2): 118-127.

29. Snow RW, Craig M, Deichmann U, Marsh K, 1999. Estimating mortality, morbidity, and disability due to malaria among Africa's non-pregnant population. Bull World Health Org 77: 624-640.

30. Kiszewski A, Teklehaimanot A, 2004. A review of the clinical and epidemiological burdens of epidemic malaria. Am J Trop Med Hyg 71 (Suppl 2): 128-135.

31. Craig MH, Snow RW, LeSuer D, 1995. A climate-based distribution model of malaria transmission in sub-Saharan Africa. Parasitol Today 15: 105-111.

32. Worrall E, Rietveld A, Delacollette C, 2004. The burden of malaria epidemics and cost-effectiveness of interventions in epidemic situations in Africa. Am J Trop Med Hyg 71 (Suppl 2): 136-140.

33. Ruger JP, Jamison DT, Bloom DE, 2001. Health and the 
economy. Merson MH, Block RE, Mills A, eds. International Public Health. Sudbury, MA: Jones and Bartlett, 619.

34. Gallup JL, Sachs JD, 2001. The economic burden of malaria. Am J Trop Med Hug 64 (Suppl 1-2): 85-96.

35. The Abuja Declaration and the Plan of Action, April 25, 2000 (http://mosquito.who.int/docs/abuja_declaration.pdf).

36. Russell S, 2004. The economic burden of illness for households in developing countries: catastrophic or manageable? A review of studies focusing on malaria, tuberculosis, and human immunodeficiency virus/acquired immunodeficiency syndrome. $A m J$ Trop Med Hyg 71 (Suppl 2): 147-155.

37. Malaney P, Spielman A, Sachs J, 2004. The malaria gap. Am J Trop Med Hyg 71 (Suppl 2): 141-146.

38. Jones C, Williams H, 2004. The social burden of malaria: what are we measuring? Am J Trop Med Hyg 71 (Suppl 2): 156-161.

39. Agyepong I, Kengeya-Kayondo J, 2004. Providing practical estimates of the malaria burden for health planners in resource poor communities. Am J Trop Med Hyg 71 (Suppl 2): 162-167.

40. Hanson K, 2004. Malaria control interventions: who should pay? Am J Trop Med Hyg 71 (Suppl 2): 168-173.

41. Barat L, Palmer N, Basu S, 2004. Do malaria control interventions reach the poor? A view through the equity lens. Am J Trop Med Hyg 71 (Suppl 2): 174-178.

42. Yeung S, Pongtavornpinyo W, Hastings IM, Mills AJ, White NJ, 2004. Antimalarial drug resistance, artemisinin-based combination therapy, and the contribution of modeling to elucidating policy choices. Am J Trop Med Hyg 71 (Suppl 2): 179-186.

43. Trape JF, 2001. The public health impact of chloroquine resistance in Africa. Am J Trop Med Hyg 64: 12-17.

44. Kolaczinski J, Mohammed N, Ali I, Ali M, Khan N, Ezard N, Rowland N, 2004. Comparison of the optimal rapid antigen test with field microsopy detection of Plasmodium vivax and $P$. falciparum: considerations for the application of the rapid test in Afghanistan. Ann Trop Med Parasitol 98: 15-20.

45. White N, 1999. Antimalarial drug resistance and combination chemotherapy. Philos Trans R Soc Lond B Biol Sci 354: 739749.

46. Laxminarayan R, 2004. Act now or later? Economics of malaria resistance. Am J Trop Med Hyg 71 (Suppl 2): 187-195.

47. Coleman P, Morel C, Shillcutt S, Goodman C, Mills A, 2004. A threshold analysis of the cost-effectiveness of artemisin-based combination therapies in sub-Saharan Africa. Am J Trop Med Hyg 71 (Suppl 2): 196-204.

48. Shepard DS, Ettling MB, Brinkmann U, Sauerborn R, 1991. The economic cost of malaria in Africa. Trop Med Parasitol 42: 199-203.

49. Snow RW, Eckert E, Teklehaimanot A, 2003. Estimating the needs for artesunate based combination therapy for malaria case management in Africa. Trends Parasitol 19: 363-369.
50. Alilio M, Kitua A, Njunwa K, Medina M, Ronn AM, Mhina J, Msuya F, Mahundi J, Depinay JM, Whyte S, Krasnik A, Bygbjerg IC, 2004. Malaria control at the district level in Africa: a case of Muheza district in northeastern Tanzania. Am J Trop Med Hyg 71 (Suppl 2): 205-213.

51. Over M, Bakote'e B, Vélayudhan R, Wilikai P, Graves P, 2004. Impregnated nets cannot fully substitute for DDT: field effectiveness of malaria prevention in Solomon Islands. Am J Trop Med Hyg 71 (Suppl 2): 214-223.

52. de Savigny D, Binka F, 2004. Monitoring future impact on malaria burden in sub-Saharan Africa. Am J Trop Med Hyg 71 (Suppl 2): 224-231.

53. Bryce J, Rongou JB, Nguyen-Dinh P, Naimoli JF, Breman JG, 1994. Evaluation of national malaria control programmes in Africa. Bull World Health Org 72: 371-381.

54. Monasch R, Reinisch A, Steketee R, 2004. Child coverage with mosquito nets and malaria treatment from population-based surveys in African countries: a baseline for monitoring progress in Roll Back Malaria. Am J Trop Med Hyg 71 (Suppl 2): 232-238.

55. Ballou R, Arevalo-Herrera M, Carucci D, Richie TL, Corradin G, Diggs C, Druilhe P, Giersing BK, Saul A, Heppner DG, Kester KE, Lanar DE, Lyon J, Hill AVS, Pan W, Cohen JD, 2004. Update on the clinical development of candidate malaria vaccines. Am J Trop Med Hyg 71 (Suppl 2): 239-247.

56. Hoffman SL, Goh LM, Luke TC, Schneider I, Le TP, Doolan DJ, Sacci J, de la Vega P, Dowler M, Paul C, Gordon DM, Stoute JA, Church LW, Sedegah M, Heppner DG, Ballou WR, Richie TL, 2002. Protection of humans against malaria by immunization with radiation-attenuated Plasmodium falciparum sporozoites. J Infect Dis 185: 1155-1164.

57. Moree M, Ewart S, 2004. Policy challenges in malaria vaccine introduction. Am J Trop Med Hyg 71 (Suppl 2): 248-252.

58. Ijumba J, Kitua A, 2004. Enhancing the application of effective malaria interventions in Africa through training. Am J Trop Med Hyg 71 (Suppl 2): 253-258.

59. Royall J, Bennett M, van Schayk I, Alilio M, 2004. Tying up lions: Multilateral Initiative on Malaria Communications; the first chapter of a malaria research network in Africa. Am J Trop Med Hyg 71 (Suppl 2): 259-267.

60. Alilio MS, Bygbjerg I, Breman JG, 2004. Are multilateral malaria research and control programs the most successful? Lessons from the past 100 years. Am J Trop Med Hyg 71 (Suppl 2): 268-278.

61. Heddini A, Walgren M, Keusch G, Davies C, 2004. The Multilateral Initiative on Malaria: past, present and future. Am J Trop Med Hyg 71 (Suppl 2): 279-282. 